\title{
É POSSÍVEL ENSINAR O CERTO E O ERRADO?
}

\author{
Claudia Fenerich*
}

\section{RESUMO}

Este breve artigo procura encaminhar uma resposta contemporânea à velha questão socrático-platônica sobre a possibilidade de se ensinar a virtude. O problema é enfrentado sob a perspectiva filosófica que confere à argumentação um papel central com relação à moralidade. A partir dos pressupostos gerais da teoria da argumentação, procede-se, então, estabelecendo-se um confronto simultâneo entre essa perspectiva e as duas visões filosóficas tradicionais, a essencialista e a relativista. Como aportes teóricos principais, a título de exemplificação das tendências consideradas, bem como dos embates histórico-filosóficos travados entre elas, destacam-se aqui os pensamentos de Sócrates-Platão e Perelman.

PALAVRAS-CHAVE: Educação. Ética. Argumentação.

\section{RESUME}

Ce bref article cherche d'offrir une réponse contemporaine à la vieille question socratique-platonique sur la possibilité d'enseigner la Vertu. Le problème est affronté sous la perspective philosophique qui attribue à l'argumentation un rôle central, rélatif à la moralaité. Á partir dès préssupositions généraux de la théorie de l'argumentation, on veut établir un confront, tant à partir de cette perspective, commme de deux différentes apports

* Doutoranda em Educação pela PUC - Rio de Janeiro. 
traditionels: l'essencialiste et le relativiste. En tant que des subsides théoriques principaux, á titre d'exemplification des tendences considerées, bien comme des contrapositions historiquesphilosophiques $q u^{\prime} y$ tienent place, ressortent ici les pensées de Socrate-Platon d'après Perelman.

MOTS CLÉS: Éducation. Éthique. Argumentation.

A possibilidade ou não de se ensinar o certo e o errado é uma velha questão, que já se apresenta no Mênon, ${ }^{1}$ de Platão, exatamente nestes termos: a virtude pode ser ensinada? O problema se desdobra da seguinte forma: se não pode ser ensinada, nem adquirida pela prática, a virtude é algo que se adquire pela própria natureza humana, ou por outro meio?

No entanto, Sócrates, personagem principal desse diálogo, afirma que responder a essas questões implica primeiro em responder à outra: o que é a virtude?

Sócrates não tinha a menor dúvida de que existia o certo e o errado e de que essas eram coisas que se excluíam mutuamente, de modo que cabia procurar o exato significado de cada uma, para, assim, obter um conhecimento verdadeiro sobre elas. Para Sócrates, dada a realidade incontestável das coisas e das idéias que se apresentavam no mundo, tomar ciência, conhecer, significa apropriar-se da definição, da unidade, da essência dessas realidades.

No intuito de explicar o conhecimento, esclarecer o modo de apropriação das essências que constituem as realidades, Sócrates se vale da teoria da reminiscência, segundo a qual "toda investigação e ciência são apenas simples recordação" (Platão, 1996, p. 55), já que a alma, imortal, guarda em si a memória de todas as coisas existentes.

1 Diálogo platônico em que Sócrates expõe a Teoria da Reminiscência, concebida com o propósito de explicar a aquisição do conhecimento. 
Assim, a investigação filosófica, utilizando-se do método da maiêutica, constitui-se, para Sócrates, numa forma de se buscar, incansavelmente, a memória de um saber que se encontra esquecido na alma. Todo homem traz em si as respostas para os problemas que se apresentam. O conhecimento é inato. A questão que se apresenta, então, é: cabe a cada um buscá-lo dentro de si.

No processo de conhecimento concebido por Sócrates, tanto o interlocutor quanto o próprio diálogo estão a serviço do autoconhecimento, e em nada interferem no objeto por ele visado. A ciência é a expressão do encadeamento dos raciocínios, que conduzem de uma idéia a outra, desde o início do processo de investigação até a formulação do conceito final. Esses raciocínios, assim como as técnicas, podem ser demonstrados e aprendidos.

No entanto, nem tudo é ciência no processo de conhecimento, nem tudo é demonstrável, nem tudo é passível de ser explicitado logicamente e apreendido pela inteligência.

Ao final do Mênon, após um longo percurso em busca da resposta certa para a pergunta certa (o que é a virtude?), Sócrates responde, enfim: a virtude não é ciência, ela é opinião certa e se adquire por graça divina. A virtude é um "exclusivo favor divino", portanto, não pode ser ensinada. Antes de dar o diálogo por terminado, o mestre recorda o que já havia esclarecido no início sobre a virtude: "Só podemos compreendê-la bem quando procurarmos, antes de tudo, não como os homens a adquirem, mas o que ela é" (Platão, 1996, p. 74).

Diante da questão: "é possível ensinar a virtude?", Sócrates perguntou: o que é a virtude? Hoje, ninguém se espantaria se, diante da pergunta sobre a possibilidade ou não de se ensinar o que é o certo e o errado, alguém perguntasse: existe o certo e o errado?

A literatura produzida sobre a denominada crise da razão, ou crise da metafísica, oferece um lastro teórico que permite explicar tanto a tradicional aliança entre conhecimento e moralidade quanto a ruptura moderna entre ciência e moral, favorecendo uma compreensão sobre as relações entre conhecimento, moralidade e educabilidade no momento atual.

São muitos os aspectos, fatos, argumentos que podem ser 
relacionados com o objetivo de se sustentar a tese de que a contemporaneidade padece do mal da relativização moral. Sobre se o padecimento é crônico ou agudo podem apresentar-se controvérsias intensas. Até mesmo sobre se é adequado falar em um padecimento, ou se é melhor falar em um modo de ser contemporâneo, podem emergir posições diversas.

A razão moderna, produto da longa tradição do pensamento ocidental, recebe de Nietzsche, no século XIX, os golpes decisivos que vão determinar seus futuros (des)caminhos. Mas já na época de Sócrates, havia não só quem duvidasse da possibilidade de vir a conhecer verdadeiramente a realidade, mas também quem explicitasse a dúvida sobre a existência da própria realidade.

Górgias, um sofista, concebeu o tratado do não-ser em três teses: o ser não existe; se existisse, não poderia ser conhecido; se pudesse ser conhecido, não poderia ser comunicado.

De modo que, de alguma forma, já estava presente na Grécia Antiga o embate entre acepções teóricas antagônicas, que se expressaram em distinções filosóficas como ser e não-ser, realidade e aparência, unidade e multiplicidade, repouso e movimento, e se constituíram, historicamente, como os dois modos ocidentais tradicionais de abordar o problema do conhecimento.

No próprio Mênon, encontramos indícios claros do intenso debate teórico que se estabeleceu entre Sócrates, Platão e os sofistas, ainda em plena aurora do pensamento filosófico. Contra a doutrina erística, segundo a qual não devemos procurar o que já sabemos, pois que já o sabemos, e nem o que não sabemos, posto que não sabemos então o que devemos procurar, Sócrates afirma: "é que nos tornamos melhores, mais ativos e menos indolentes, se cremos que é um dever procurar o que ainda não sabemos, do que se considerarmos impossível e estranho ao nosso dever a busca da verdade desconhecida" (Platão, 1996, p. 61). A essas palavras, o pensador acrescenta que não pretende afirmar de modo absoluto que a teoria da reminiscência seja verdadeira, mas que afirmar que é dever do homem procurar o que ele não sabe, isso sim ele se encontra disposto a fazer de qualquer forma, com palavras e atos, contra tudo e contra todos. 
Devidamente considerada essa controvérsia histórico-filosófica, torna-se claro que uma marca própria do pensamento contemporâneo não seria nem o surgimento nem a predominância do relativismo, seja no âmbito ontológico, epistemológico ou ético/ moral, mas a proposta de uma forma inédita de pensar, uma forma não-excludente, que tem como ponto de partida a assunção das dificuldades enfrentadas pela razão no bojo do movimento histórico ocidental e como objetivo o estabelecimento de uma forma universal de entendimento. ${ }^{2}$

Na Grécia Antiga, enquanto Sócrates enfrentava os problemas buscando pela verdadeira essência da realidade, Górgias apontava os limites da razão, questionando mesmo a possibilidade de se estabelecer uma relação de conhecimento. ${ }^{3}$ Hoje, enquanto alguns pensadores sustentam a existência exclusiva da linguagem, tornando absoluta, e, assim, totalmente nula, sua tese sobre a relativização, outros situam a problemática contemporânea entre o realismo e o subjetivismo, propondo enfrentá-la com uma concepção que difere tanto daquela que afirma que o ser é algo determinado, fixo, uno e igual, quanto da que afirma que o ser é mera representação.

Responder à pergunta sobre se é possível ou não ensinar o certo e o errado, de acordo com esses últimos, pressupõe considerar que se pode distinguir entre essas duas coisas. Quer dizer, pressupõe que, de alguma forma - ainda que não pura e exclusivamente, como pretendeu Sócrates - existe algo que é certo e algo que é errado, e, ainda, que, mesmo não sendo fixos nem absolutos, existem critérios objetivos que podem guiar a distinção entre uma e outra coisa.

2 Numa abordagem genérica, integram-se a esse movimento teórico que retoma o ideal moderno de uma razão universal, pensadores do século $X X$ que conferiram à argumentação um papel central na sua obra, como Perelman, Karl-Otto Apel, Habermas.

3 Sobre o sentido da afirmação de Górgias ("nada existe; se existisse, não poderia ser conhecido; se pudesse ser conhecido, não poderia ser comunicado"), há diferentes interpretações. Certos autores consideram que ele apenas pretendia apontar os limites da razão e não sua total impotência, como pretenderam os cépticos. 
No artigo Enfoques, inserción curricular y metodologia para la Educación Etica y Ciudadana, Obiols (1997) afirma que o desafio atual da educação moral é alcançar um equilíbrio entre o tradicionalismo e o relativismo, numa nova forma de atuação, que guarde distância dos perigos inerentes às outras duas formas extremas. ${ }^{4}$ Conforme o autor, o tradicionalismo moral supõe que a sociedade desviou-se do caminho correto, que houve uma perda dos bons valores e que é necessário recuperá-los e reconduzir a sociedade ao caminho correto. Já o relativismo moral, pelo contrário, considera que não há norma alguma, que tudo depende da perspectiva por onde se vêem as coisas. À primeira forma de conceber o problema, relaciona-se uma educação moral que constitui em introduzir os educandos em um código determinado de conduta, por meio de exemplos, no contexto de um legado de virtudes socialmente consideradas. À segunda maneira de conceber a problemática moral, aplica-se, de acordo com a distinção feita pelo autor entre moral e ética, uma educação ética que tem como base a simples consideração das diversas opiniões que compõem a cena social.

Como alternativa para esses dois extremos de atuação pedagógica, que oscilam entre a doutrinação moral e a negação de princípios éticos, Obiols (1997, p. 19) apresenta a doutrina dos direitos humanos, conforme essa é compreendida por uma vertente da filosofia contemporânea, para a qual

[...] na esfera da moral e da política não há ordem natural, quer dizer, a moral e a política são o produto da criação racional do homem, embora já não se trate da criação de uma razão transcendental infalível, senão que de uma razão

4 O citado artigo faz parte de uma coletânea Formación Ética y Ciudadana (1997), na qual diversos autores discutem questões relativas à implementação da proposta que se apresenta no capítulo de Formación Ética y Ciudadana en la Educación, introduzido nos documentos curriculares da Argentina, a partir do ano de 1995, no contexto do movimento de atualização curricular então desenvolvido no país. 
argumentativa e dialógica, que somente tem a aspiração de chegar a ter validez universal enquanto produto da contraposição de argumentações em um diálogo do qual não pode ser excluído nenhum dos membros da comunidade".

Em sociedades democráticas maduras, diz Obiols (1997, p. 20): “[...] o desenvolvimento moral dos indivíduos consiste num progresso no sentido da racionalidade, quer dizer, na aceitação ou não aceitação dos códigos sociais por razões, e não por mera disciplina diante das convenções da tradição ou por temor às pressões do grupo".

Para Obiols (1997), por conta dos valores de que é porta-voz e sobre os quais se sustenta (a autonomia, o pluralismo, o respeito mútuo e a consideração racional dos problemas), esta "ética aberta", cujos pressupostos são tão falíveis quanto objetivos, é uma ética substantiva, não apenas formal.

A partir das considerações de Obiols, examinemos mais atentamente a questão sobre a possibilidade de se ensinar ou não o certo e o errado. Como foi mostrado na primeira parte deste trabalho, de acordo com Sócrates, para se responder a essa questão é necessário, antes, saber o que é o certo e o que é o errado. No entanto, responder hoje a essa questão, buscando a essência única e a priori dessas noções, é simplesmente impossível, pois uma marca do mundo atual é a coexistência de diversas visões de mundo, a convivência entre muitas formas de vida. Ao mesmo tempo, afirmar que tudo é relativo e negar a existência de princípios que possam guiar nosso juízo por entre a multpilicidade de opiniões que se apresentam significa simplesmente aceitar que todas as ações humanas, indiscriminadamente, são igualmente legítimas e merecem ser praticadas.

Essas duas posições refletem extremos teóricos cujas conseqüências práticas nem sempre alcançam o devido esclarecimento. Em alguns momentos, em meio a tantas dificuldades teóricas, simplesmente paro e pergunto-me quantas vezes as pessoas já se perguntaram seriamente o que significa, na prática, negar qualquer princípio, abrir mão de qualquer 
possibilidade de se fundamentar o que é certo e o que é errado. $\mathrm{O}$ problema da moralidade - e mais ainda da educação moral hoje sem dúvida não é de fácil solução, mas seus efeitos podem se tornar tão devastadores que é recomendável prosseguir e insistir em enfrentá-lo.

Retomando: por um lado, não se pode, hoje, definir de modo absoluto o que é o certo e o errado; por outro, não se pode abrir mão de princípios que permitam discernir entre as duas noções. Por isso, para fugir tanto de uma educação moral que prescreve regras de conduta quanto de um relativismo desastroso, Obiols (1997), tomado a título de exemplo neste artigo, propõe uma educação ética baseada em princípios racionais que orientam a ação. No lugar de prescrever o que é correto ou não fazer, ou de acolher indiscriminadamente todas as opiniões, a atuação pedagógica com o objetivo da formação ética envolve o educando em um diálogo constante que visa ao desenvolvimento de sua capacidade racional, por meio do exercício da argumentação.

No entanto, esse diálogo pedagógico que capacita para a argumentação não é apenas uma forma racional na qual tudo cabe. Obiols (1997) compreende a máxima relevância desse aspecto e afirma de forma contundente que trata-se de uma "ética aberta", mas substantiva. Ou seja, uma ética de razões, contextualizadas, históricas, contingentes, culturais, mas fundamentada em valores universais.

É fato que não se pode falar em certo e errado sem estabelecer determinados critérios de julgamento. Mas, esses critérios são racionais? Que relação se estabelece entre razão e valor no contexto de um projeto que visa à possibilidade de entendimento universal?

Perelman (1996) diz estar convicto de que todo valor, além de ser arbitrário e logicamente indeterminado, não resulta de uma experiência, nem pode ser deduzido de princípios incontestáveis. No entanto, de posse dessa convicção, Perelman se pergunta: "Mas cumprirá tirar disso a conclusão bem mais geral, a saber, que os valores e as normas fundamentais que nos guiam a ação são alheios a qualquer racionalidade, que não podemos nem criticá-los nem 
justificá-los, que toda deliberação a propósito deles não passa da expressão de nossos interesses e de nossas paixões?" (1996, p. 183).

Os estudos de Perelman (1996) levam-no necessariamente a confirmar: dentro de uma concepção racionalista estrita, que reconhece apenas a dedução e a indução como métodos e o cálculo e a experiência como referências, é impossível raciocinar sobre valores. Reza a tese dos filósofos positivistas, de Hume ${ }^{5}$ até Ayer: devemos renunciar a todo uso filosófico da razão prática, limitando-nos, na ação, a um uso técnico da razão, a um ajuste dos meios aos fins, que são, por sua vez, irracionais.

O paradoxo da modernidade também pode ser expresso da seguinte forma: "[...] a crítica da metafísica, do Renascimento em diante, e a absolutização da ciência como forma de conhecimento levaram, em variantes positivistas e neopositivistas, a considerar que o mundo moral era um mundo alheio ao método científico e assim, de acordo com tais concepções, à razão" (OBIOLS, 1997, p. 17).

Diante disso, devemos, então, nos resignar a considerar definitivamente impossível o objetivo da tradição filosófica ocidental de encontrar um fundamento racional para a ação individual e coletiva? Se é fato que a lógica moderna não compreende o raciocínio sobre os valores, também é fato que Perelman não estava disposto a se limitar a ela e a abrir mão de compreendê-los. O resultado disso foi a descoberta de uma possibilidade que permitiu ir além da limitação imposta pela lógica moderna. Perelman concebeu-a a partir da leitura dos antigos tratados de retórica e dos Tópicos aristotélicos:

Um amplo estudo, empírico e analítico, permitiu-nos apresentar essa lógica não-formal, que é uma teoria da argumentação complementar da teoria da demonstração, objeto da lógica formal. [...] Nossos trabalhos nos

5 A rigor, Hume foi um empirista céptico. A referência ao autor, feita por Perelman, neste ponto, tem o intuito de vinculá-lo à vertente positivista, como um precursor dela. 
convenceram de que não existe lógica específica atinente aos valores, mas existem as mesmas técnicas de raciocínio que utilizamos para criticar e para justificar opiniões, escolhas, pretensões e decisões, enunciados que qualificamos habitualmente de juízos de valor (1996, p. 184).

A conclusão de Perelman confere à argumentação um novo e central papel no pensamento contemporâneo: "O uso prático da razão não pode ser compreendido sem o integrar numa teoria geral da argumentação" (PERELMAN, 1996, p. 185, nota6).

A teoria da argumentação permite compreender a especificidade do processo de justificação. A relação com valores é de adesão, escolha, e essa não é totalmente arbitrária. Os princípios não são nem evidentes, como queriam os realistas, nem totalmente arbitrários, como queriam os nominalistas: ${ }^{6}$ a eles se adere e essa adesão pode ser justificada.

Para transcender o particular, para ser válida para todos, uma justificação deverá ser racional ou, pelo menos, razoável. E, de acordo com as palavras de Perelman:

Admitir a possibilidade de uma justificação racional ou razoável significa reconhecer, com isso, um uso prático da razão. [...] Já não é limitar esta, como queria Hume, a um uso teórico, à capacidade de descobrir a verdade ou o erro. É reconhecer que raciocinar não é somente verificar e demonstrar, é também deliberar, criticar e justificar, é apresentar razões pró e razões contra, é, numa palavra, argumentar (PERELMAN, 1996, p. 186).

Depois das idéias até então expostas, afinal, como responder, de forma sintética e clara, à pergunta sobre se é possível ou não ensinar o certo e o errado?

6 No texto Cinco aulas sobre a justiça, Perelman denomina a visão oposta ao realismo de convencionalista ou nominalista, além de adjetivá-la como subjetiva e arbitrária. $\mathrm{O}$ autor qualifica a visão realista de objetiva e dogmática. 
Primeira coisa importante a ser dita (e que o será sempre, necessariamente, por todos aqueles que partilham da idéia de que o conhecimento é provisório, falível e se faz e refaz em um debate constante) é que não se pretendeu com este artigo, como, aliás, não se poderia mesmo pretender, formular uma resposta definitiva para a questão abordada. Nesse sentido, é oportuno acrescentar que este breve artigo também não oferece uma visão satisfatoriamente representativa da intensa produção de que se dispõe atualmente na área. Longe de apresentar a multiplicidade de enfoques e abordagens existentes, este artigo concentrou esforços na tentativa de enfrentar o problema sob a perspectiva filosófica que confere à argumentação um papel central com relação à moralidade. Mais precisamente, buscou-se fazer isso estabelecendo um confronto simultâneo entre essa determinada perspectiva e as duas visões filosóficas tradicionais, a essencialista e a relativista. Para isso foram utilizados, em linhas absolutamente gerais, como aportes teóricos principais, a título mesmo de exemplificação das tendências consideradas, bem como dos embates travados entre elas, os pensamentos de Sócrates-Platão e Perelman.

Segundo aspecto a ser considerado nessa conclusão, conseqüência quase natural do que foi exposto anteriormente, é que a formulação da resposta à questão aqui tratada adquire mais uma forma interrogativa do que afirmativa, constituindo-se mais propriamente um questionamento articulado do que uma exposição sobre o tema.

Enfim, vamos lá: é possível ensinar o certo e o errado?

Para Sócrates e Platão, representantes aqui de uma abordagem realista ou essencialista, o problema se resolve da seguinte forma: não é possível ensinar, porque o certo e o errado não são noções que podem ser adquiridas pela experiência nem pela inteligência comum. O certo e o errado são noções absolutas, que só podem ser devidamente compreendidas pelo homem virtuoso. O homem virtuoso, somente ele, é um homem a quem os deuses concedem a suprema graça de conhecer e ao mesmo tempo de exercer a bondade, a beleza e a justiça.

Para adeptos da corrente relativista, oposta ao essencialismo, 
neste artigo exemplificada apenas pelo sofista Górgias, o problema também se resolve com a afirmação de que não é possível ensinar o que é certo e o que é errado. Mas aqui a justificativa é outra: não há nenhum critério que permita discernir o certo e o errado, tudo não passa de uma questão de ótica e de opinião, não há referência concreta para sustentar a primazia de um ponto de vista sobre $o$ outro.

Para responder de acordo com os pressupostos gerais dos teóricos contemporâneos da argumentação, aqui representados por Perelman, devemos considerar fortemente a possibilidade de se ensinar o que é o certo e o que é o errado. É claro que nesse sentido não se trata de um ensino dogmático, definitivo, baseado em conceitos absolutos, mas sim de um ensino histórica e socialmente situado. ${ }^{7}$ Nesse ponto, cabe também uma ressalva: Aristóteles, já na Grécia Antiga, também vai defender a posição de que é possível ensinar a virtude, apontando para uma compreensão de que essa pode ser adquirida pelo hábito. Aristóteles desvincula-se, nesse e em outros tantos aspectos, da tradição platônico-socrática, afirmando, por exemplo - contra a tese central de Platão segundo a qual quem conhece o bem pratica o bem - que um homem pode conhecer o bem e praticar o mal.

Mas vamos nos ater agora somente ao pressuposto mais geral da argumentação, aquela idéia básica que, sem maiores problemas, pode ser compartilhada pelas diversas linhas que integram o trabalho filosófico nessa área. Essa nada mais é do que a tese de que a linguagem, mais do que meio de expressão do saber, é um aspecto constitutivo do saber. Dessa premissa, deriva a não menos importante e consensual idéia de que a linguagem é o meio privilegiado de entendimento, uma vez que é uma capacidade

7 Nesse ponto da discussão, o conceito de auditório de Perelman contribui bastante, pois são os diferentes auditórios que podem celebrar (ou não) acordos sobre os critérios que servirão para balizar as diferenças entre o certo e o errado. O conceito de auditório universal é desenvolvido em vários textos, mas pode ser facilmente localizado no parágrafo 7 da primeira parte do Tratado da Argumentação (1996), de Perelman e Lucie Olbechts-Tytace. 
universal, presente em todos os homens, de todas as épocas e culturas.

Para nós, contemporâneos, o certo e o errado não são realidades que se encontram além da experiência, esquecidas na alma ou em qualquer outro lugar, aguardando serem apreendidas num esforço investigativo autêntico, exercido pelo homem divinamente dotado do poder de conhecer. Para nós, o certo e o errado são noções construídas individual e coletivamente, com o propósito de orientar nossa ação, que acarreta sempre conseqüências. São noções que podem e devem ser desenvolvidas por todos, a partir de princípios compartilhados e assim tornados objetivos.

O certo e o errado são ensinados no contexto da vida social, por todas as instituições criadas com o objetivo de formar e regular a subjetividade. Para nós, atualmente, o certo e o errado não são noções que se aprendem simplesmente pelo exemplo, vindo do professor, ou de qualquer outra autoridade, mas são noções que devem ser estabelecidas com base em critérios racionais, que podem ser justificados, argumentados, questionados.

É possível ensinar o certo e o errado todas as vezes em que nos dispomos a aprender com o outro. Pois, aprender com o outro supõe conceder-lhe o direito de expressão, respeitá-lo como interlocutor, relevar o seu ponto de vista, compartilhar, compreender.

Isso posto, podemos retomar novamente a questão: é possível ensinar o certo e o errado? Finalmente, podemos afirmar com certeza que não há como respondê-la, sem antes considerar os seguintes desdobramentos: 1) o que é o certo e o que é o errado? 2) quem vai ensinar? 3) de que forma vai ensinar?

\section{Referências}

OBIOLS, G. A. Enfoques, inserción curricular y metodologia para la Educación Etica y Ciudadana. In: ARCHIDEO, L. B.; CASULLO, M. M.; ROZAS, A. F. O. de; GROISMAN, E. I.; GUARIGLIA, O.; OBIOLS, G.; DECIBE, S. B. (prologuista). La Formación Ética y Ciudadana. Argentina: Ediciones Novedades Educativas, 1997. 
OLIVEIRA, R. J. de. Conhecimentos confiáveis em educação repensando o papel das teorias pedagógicas. Espaço informativo técnico-científico do INES, Rio de Janeiro, n. 23, jan./jun. 2005.

PERELMAN, C. Cinco aulas sobre a justiça. In: Ética e Direito. São Paulo: Martins Fontes, 1996.

; OLBECHTS-TYTACE, L. Tratado da Argumentação. A Nova Retórica. São Paulo: Martins Fontes, 1996. . Lógica e Retórica. In: Retóricas. São Paulo: Martins Fontes, 1997.

PLATÃO. Mênon. Rio de Janeiro: Ediouro, 1996.

Data de registro 20/12/06 Data de aceite 09/02/07 